\title{
The Evaluation of Solar Contribution in Solar Aided Coal-Fired Power Plant
}

\author{
Rongrong Zhai, Yongping Yang, Yong Zhu, and Denggao Chen \\ School of Energy Power and Mechanical Engineering, North China Electric Power University, Beijing 102206, China \\ Correspondence should be addressed to Rongrong Zhai; zhairongrong@gmail.com
}

Received 17 October 2012; Revised 11 January 2013; Accepted 29 January 2013

Academic Editor: Kalvala Srinivas Reddy

Copyright (c) 2013 Rongrong Zhai et al. This is an open access article distributed under the Creative Commons Attribution License, which permits unrestricted use, distribution, and reproduction in any medium, provided the original work is properly cited.

Solar aided coal-fired power plants utilize various types of solar thermal energy for coupling coal-fired power plants by using the characteristics of various thermal needs of the plants. In this way, the costly thermal storage system and power generating system will be unnecessary while the intermittent and unsteady way of power generation will be avoided. Moreover, the large-scale utilization of solar thermal power and the energy-saving aim of power plants will be realized. The contribution evaluating system of solar thermal power needs to be explored. This paper deals with the evaluation method of solar contribution based on the second law of thermodynamics and the principle of thermoeconomics with a case of $600 \mathrm{MW}$ solar aided coal-fired power plant. In this study, the feasibility of the method has been carried out. The contribution of this paper is not only to determine the proportion of solar energy in overall electric power, but also to assign the individual cost components involving solar energy. Therefore, this study will supply the theoretical reference for the future research of evaluation methods and new energy resource subsidy.

\section{Introduction}

Since the energy crisis in the 1970s, the major developed countries of the world started a series of projects involving solar thermal power generation for energy substitution. Among the developments in this field, the research of America, Israel, Spain, Germany, and Italy began first and are consequently the most mature [1]. Solar energy as a form of clean energy has broad application prospects. Moreover, coupling with coal-fired power plants as a type of solar power utilization has been presented and investigated by many researchers.

Pai proposed the integration of a solar concentrator field to a $210 \mathrm{MWe}$ coal-fired power plant [2]. Gupta and Kaushik found that using solar energy as a substitute for feed water heaters is more advantageous than using solar energy alone for power generation [3]. From a theoretical perspective, the solar aided coal-fired power generation system has many advantages when compared with a photovoltaic power generation system. However, the popular utilization of this technology has been relatively slow. The reasons for this apathetic uptake have been concluded as follows: (a) variations of solar radiation can cause operation difficulties and (b) no reasonable evaluating systems have been built for the contribution of solar energy in the integrated system. The study about solar aided coal-fired power generation system mostly concentrates on performance analyses, integration modes, operations optimization, and so on. Since Gaggioli and El-Sayed comprehensively concluded the history of second law costing method, thermoeconomic analysis has become a powerful scheme applied extensively in design, operation, and reform of energy systems $[4,5]$. Though thermoeconomic methods are multitudinous, the objectives of most existing analysis techniques still can be included in the determination of (a) the appropriate allocation of economic resources to optimize the design and operation of a system and (b) the economic feasibility and profitability of a system [6]. The methods can be roughly divided into two classes: algebraic methods and calculus methods $[4,5]$. The thermoeconomic analysis of solar aided coal-fired power 
generation system has already begun. Suresh and Reddy dealt with the 4-E (namely, energy, exergy, environment, and economic) analysis of solar aided coal-fired power plants with a subcritical and a supercritical power plant as references [7]; Baghernejad and Yaghoubi presented a new thermoeconomic method applying a genetic algorithm for optimization of an integrated solar combined cycle system [8].

The previous research as mentioned above has investigated the integration of a solar concentrator field with a power plant. However the integrated system introduces solar energy into the individual components in the traditional power plants, the researches about how to evaluate the contribution of solar energy in the system are hardly found.

A thermoeconomic method of evaluating solar contribution in the integrated system is firstly proposed in this paper. A new built $600 \mathrm{MW}$ solar aided coal-fired power generation unit is considered as a reference power plant. According to the design parameters, the contribution proportion has been achieved, and the generation cost has also been explored by using sensitivity analysis method.

\section{System Descriptions and the Proposed Problem}

Figure 1 shows the diagram of the solar aided coal-fired power plant. In the solar field, several parabolic trough collectors are connected and the heating material is heat transfer oil. The oil-heat exchanger is a tube-shell heat exchanger. The parabolic trough collectors and the oil-heat exchanger together are called solar driven oil-water heat exchanger in this paper.

In a typical reheated steam coal-fired power plant, the combustion of coal takes place in the boiler. The unsaturated boiler feedwater from the condenser enters the boiler after going through four low-pressure reheaters (HTR1, HTR2, HTR3, and HTR4), three high-pressure reheaters (HTR5, HTR6, and HTR7), and a deaerator (Deaerator). The outlet superheated steam from the boiler is transported to the high-pressure cylinder to produce power, then, after being reheated in the boiler, drives the intermediate and lower pressure cylinders. Finally, the exhaust is condensed in the condenser. It can be seen from Figure 1 that the extractions from different positions of the cylinders ((1)-(8)) are used to heat the feedwater via feedwater reheaters. The $600 \mathrm{MW}$ solar aided coal-fired power plant is similar to the reheated steam cycle system. The difference lies in that a solar aided oil-water heat exchanger has been added. When the solar radiation is strong (e.g., in the day), the steam extraction (1) is cut off and HTR7 will not be in operation; the feedwater will be heated in the oil-heat exchanger. Conversely, when the solar radiation is week (e.g., in the night), the oil-heat exchanger will not be in operation and the plant will operate in the same manner as the base plant. In the solar field (as shown in the dash block in Figure 1), several parabolic collectors are connected using heat transfer oil as the heating medium in a tube-shell heat exchanger. The parabolic collectors and the oil-heat exchanger together are called solar driven oil-water heat exchanger (SDOHE) in this paper.
It can be seen from Figure 1 that the solar contribution concentrates on providing heat to the feedwater. After heating, the feedwater flows into the boiler, then, after a series of processes, the thermal energy is finally translated into electrical power.

The principle behind the solar aided coal-fired power generation system is to supply thermal energy by substituting high pressure feedwater heaters with oil-water heat exchangers. During a series of circulation, the energy contributes to the system power output indirectly. Therefore, it is meaningful to discuss how to evaluate the solar energy contribution in the solar aided coal-fired power plant.

\section{Evaluation Model of Solar Energy Contribution}

According to the first and second laws of thermodynamics, evaluation models based on energy balance and exergy balance are the possible methods for evaluating energy contribution such as solar energy and fuel. The method based on energy balance just considers the magnitude of energy without taking energy grade into account. The evaluation based on exergy balance has added energy grade to the system, while the nonequivalence of the same value of exergy at different points in the system has never been considered. Therefore, the evaluation based on the index of technical economics and energy equivalence has been explored in this study. The approach proposed in this paper is called the thermoeconomic cost method, considering both the energy grade and the nonequivalence.

The thermoeconomic cost method includes three steps as shown in Figure 2. Firstly, the contribution proportions of solar energy and coal in every exergy flow needs to be confirmed. Secondly, according to the thermoeconomic concept, the values of each cost flow can be achieved. Thirdly, the contribution of solar economic cost will be calculated with the above data.

3.1. Confirming the Ratio of Solar Energy against Coal according to Each Exergy Flow. This part is shown in Figure 2, Box 1. For the convenience of the analysis, Figure 1 has been simplified as shown in Figure 3. The system includes six subsystems: (1) oil-water heat exchanging driven by solar energy; (2) boiler preheating, steam generating, and superheating; (3) high-pressure cylinder of turbine; (4) boiler reheating; (5) intermediate- and low-pressure cylinder of turbine; and (6) heat exchanging. The main parameters of the system such as the temperature, enthalpy, and flow rate are listed in Figure 3.

The exergy balance equation of each subsystem is as follows.

(1) The exergy loss of oil-water heat exchanging is given by $E_{9}+E_{6}-E_{1}$.

The proportion of solar exergy loss assumed to be $\delta_{1}$. Then the loss will be, $\delta_{1}\left(E_{9}+E_{6}-E_{1}\right)$, and the exergy loss of feedwater will be, $\left(1-\delta_{1}\right)\left(E_{9}+E_{6}-E_{1}\right)$.

The exergy achieved by water will be written as follows: $E_{1}-E_{6}+\left(1-\delta_{1}\right)\left(E_{9}+E_{6}-E_{1}\right)$. 


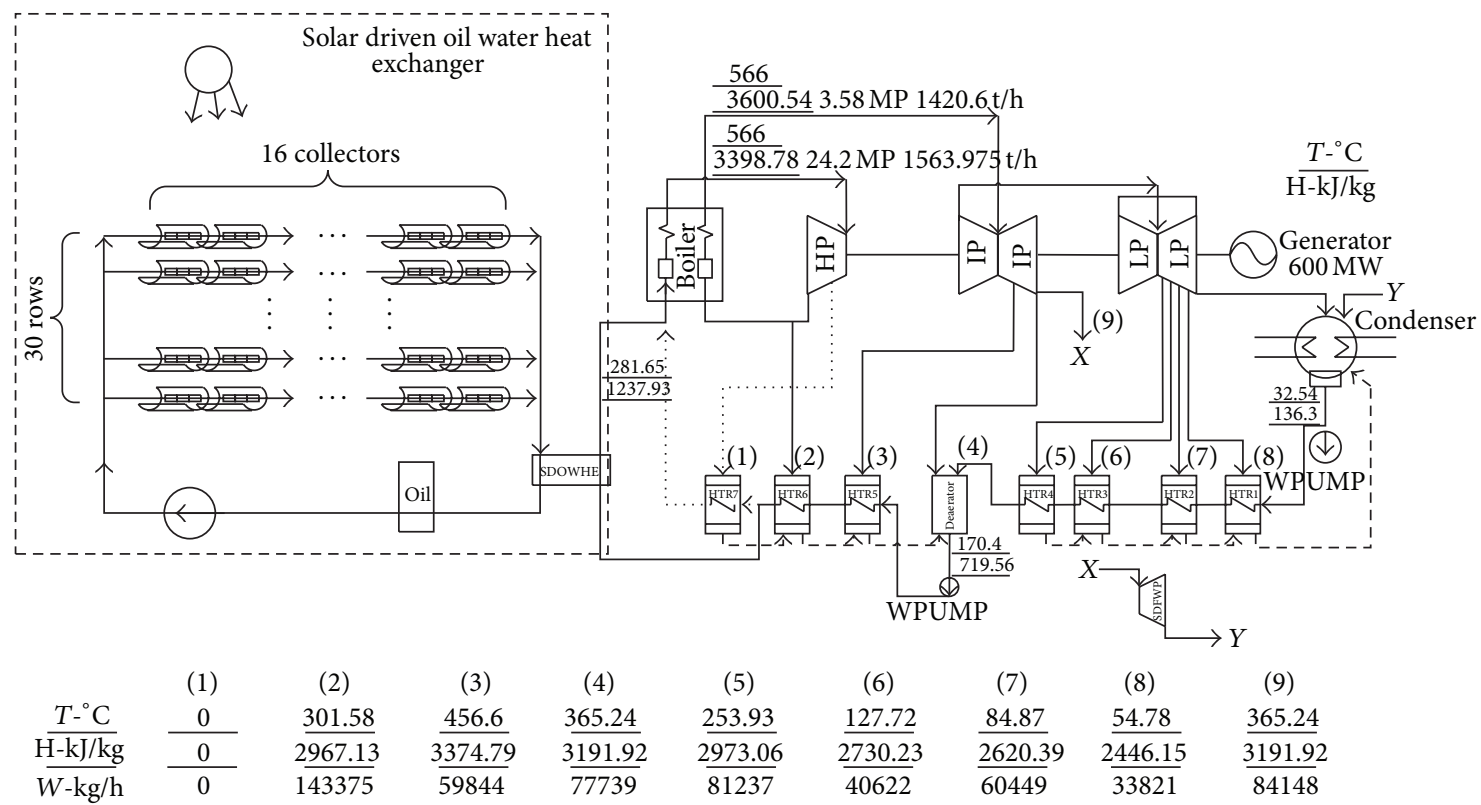

FIGURE 1: Layout of the solar aided coal-fired power plant.

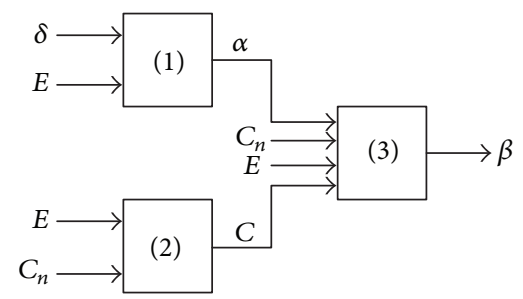

FIGURE 2: Schematic representation of the calculating process of the thermoeconomic cost evaluation.

It equals the exergy released by solar energy, which may be written as follows: $E_{9}-\delta_{1}\left(E_{9}+E_{6}-E_{1}\right)$. follows:

The proportion of solar energy at point 1 may become as

$$
\begin{aligned}
\alpha_{1}=( & \alpha_{6}\left[-\left(1-\delta_{1}\right) E_{9}+\delta_{1} E_{6}+\left(1-\delta_{1}\right) E_{1}\right] \\
& \left.+\left(1-\delta_{1}\right) E_{9}-\delta_{1} E_{6}+\delta_{1} E_{1}\right)\left(E_{1}\right)^{-1} .
\end{aligned}
$$

(2) The total exergy loss of preheater, steam generator and superheater is given by $E_{10}+E_{1}-E_{2}$.

The proportion of coal exergy loss assumed to be $\delta_{2}$.

Then the exergy loss of water will be, $\left(1-\delta_{2}\right)\left(E_{10}+E_{1}-E_{2}\right)$, and the exergy achieved by water will be written as follows: $E_{2}-E_{1}+\left(1-\delta_{2}\right)\left(E_{10}+E_{1}-E_{2}\right)$.

It equals the exergy released by coal, which may be written as follows: $E_{10}-\delta_{2}\left(E_{10}+E_{1}-E_{2}\right)$.

The proportion of solar energy at point 2 may become as follows:

$$
\alpha_{2}=\frac{\alpha_{1}\left[-\left(1-\delta_{2}\right) E_{10}+\delta_{2} E_{1}+\left(1-\delta_{2}\right) E_{2}\right]}{E_{2}} .
$$

(3) The proportions of solar energy at the import and export of turbine are equal.
For the third subsystem, the equation will be given by

$$
\alpha_{3}=\alpha_{2}=\alpha_{7}
$$

For the fifth subsystem, the equation will be given by

$$
\alpha_{5}=\alpha_{4}=\alpha_{8} .
$$

(4) The total exergy loss of reheater is given by $E_{11}+E_{3}-$ $E_{4}$.

The proportion of coal exergy loss assumd to be $\delta_{3}$.

Then the exergy loss of coal will be $\delta_{3}\left(E_{11}+E_{3}-E_{4}\right)$, and the exergy loss of water will be $\left(1-\delta_{3}\right)\left(E_{11}+E_{3}-E_{4}\right)$.

The exergy achieved by water will be written as follows: $E_{4}-E_{8}+\left(1-\delta_{3}\right)\left(E_{11}+E_{3}-E_{4}\right)$.

It equals the exergy released by coal, which may be written as follows: $E_{11}-\delta_{3}\left(E_{11}+E_{3}-E_{4}\right)$.

The proportion of solar energy may become as follows:

$$
\alpha_{4}=\frac{\alpha_{3}\left[-\left(1-\delta_{3}\right) E_{11}+\delta_{3} E_{3}+\left(1-\delta_{3}\right) E_{4}\right]}{E_{4}} .
$$

(5) The total exergy loss is given by $E_{5}+E_{7}+E_{8}-E_{6}$.

The proportions of exergy loss at point 7 and 8 are assumed to be $\delta_{4}$ and $\delta_{5}$. 


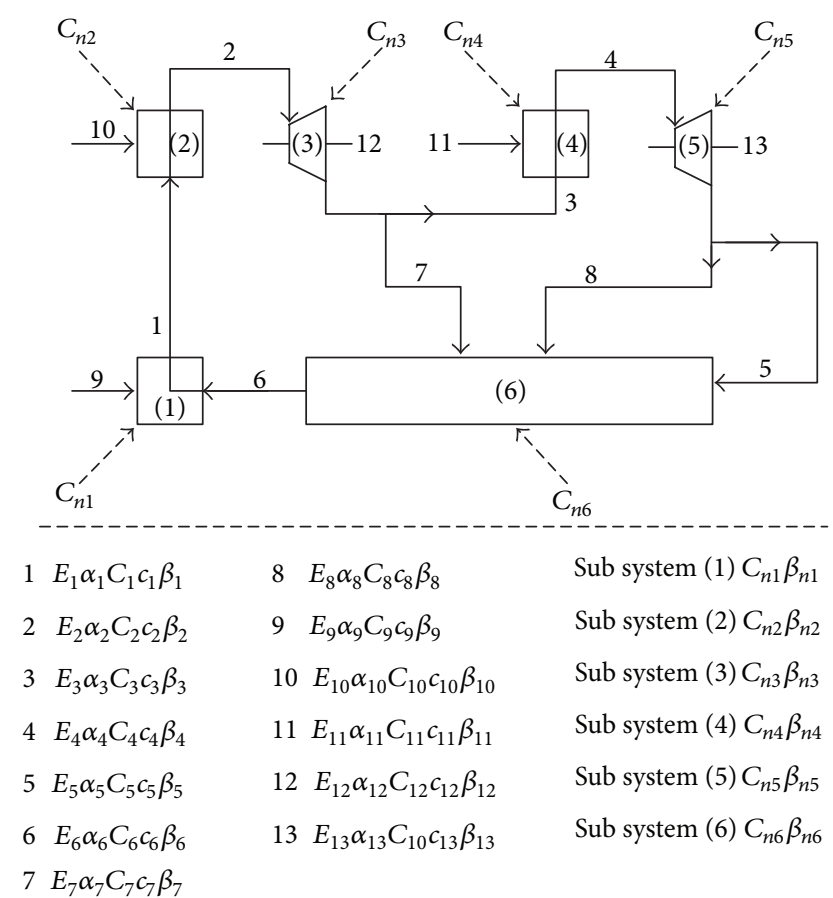

\begin{tabular}{|c|c|c|c|c|c|c|c|c|}
\hline & (1) & (2) & (3) & (4) & (5) & $(6)$ & $(7)$ & (8) \\
\hline Temperature - ${ }^{\circ} \mathrm{C}$ & 281.7 & 566 & 301.6 & 566 & 32.4 & 240.8 & 301.6 & 272.4 \\
\hline Enthalpy-kJ/kg & 1237.9 & 3398.8 & 2967.1 & $\underline{3600.5}$ & 2324.3 & 1048.9 & 2967.1 & 2324 \\
\hline Flow rate-kg/h & 1563975 & 1563975 & 1420600 & 1420600 & 982740 & 1563975 & 143375 & 437860 \\
\hline
\end{tabular}

FIGURE 3: Schematic representation of solar aided coal-fired power generation system. $\left.E_{6}\right)$.

Then, the exergy loss at point 7 will be $\delta_{4}\left(E_{5}+E_{7}+E_{8}-\right.$

The exergy loss at point 8 will be $\delta_{5}\left(E_{5}+E_{7}+E_{8}-E_{6}\right)$, and the exergy loss at point 5 will be $\left(1-\delta_{4}-\delta_{5}\right)\left(E_{5}+E_{7}+E_{8}-E_{6}\right)$.

The equation will be written as follows:

$$
\begin{aligned}
\alpha_{6}=( & \alpha_{7}\left[E_{7}-\delta_{4}\left(E_{5}+E_{7}+E_{8}-E_{6}\right)\right] \\
+ & \alpha_{8}\left[E_{8}-\delta_{5}\left(E_{5}+E_{7}+E_{8}-E_{6}\right)\right] \\
+ & \alpha_{5}\left[E_{5}-\left(1-\delta_{4}-\delta_{5}\right)\right. \\
& \left.\left.\quad \times\left(E_{5}+E_{7}+E_{8}-E_{6}\right)\right]\right)\left(E_{6}\right)^{-1} .
\end{aligned}
$$

The proportion of solar energy will be ensured by using (1)(6).

3.2. The Exergy Follow Cost C Will Be Ensured by Thermoeconomic Analysis. This part is shown in Figure 2, Box 2. According to Figure 3, the system includes 6 subsystems and 13 exergy flows. The equation satisfied by each subsystem is given by:

$$
C_{\text {in }}+C_{n}=C_{\text {out }} \text {, }
$$

where $C_{\text {in }}$ and $C_{n}$ are, respectively, the energy cost of import and the cost of others, and $C_{\text {out }}$ is the energy cost of export.

Then, for the first subsystem, the equation is given by the following:

$$
C_{6}+C_{9}+C_{n 1}=C_{1}
$$

For the second subsystem, the equation is given by the following:

$$
C_{1}+C_{10}+C_{n 2}=C_{2} .
$$

For the third subsystem, the equation is given by the following:

$$
C_{2}+C_{n 3}=C_{3}+C_{7}+C_{12}
$$

For the fourth subsystem, the equation is given by the following:

$$
C_{3}+C_{11}+C_{n 4}=C_{4} .
$$

For the fifth subsystem, the equation is given by the following:

$$
C_{4}+C_{n 5}=C_{5}+C_{8}+C_{13} .
$$

For the fifth subsystem, the equation is given by the following:

$$
C_{5}+C_{7}+C_{8}+C_{n 6}=C_{6} .
$$

The cost of solar exergy flow $E_{9}$ is given data, and then we will get the equation as follows:

$$
\frac{C_{9}}{E_{9}}=c_{9} .
$$




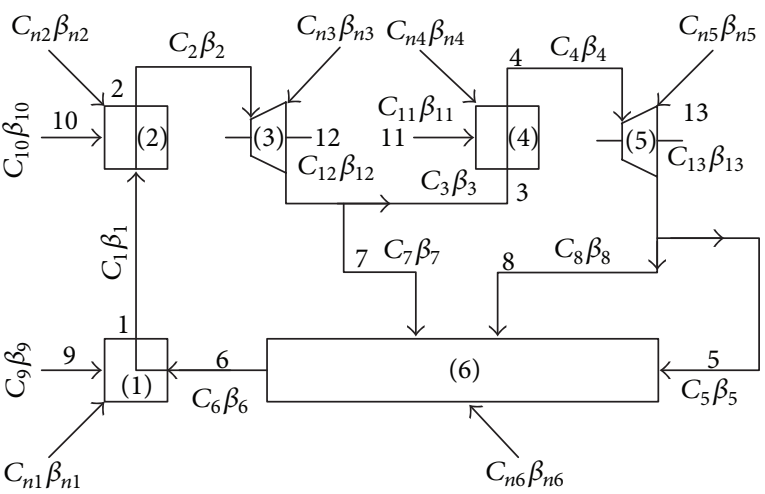

FIGURE 4: The schematic of cost flows.

The costs of coal exergy flows $E_{10}$ and $E_{11}$ are given data, and then the equation will be as follows:

$$
\frac{C_{10}}{E_{10}}=\frac{C_{11}}{E_{11}}=c_{10}=c_{11} .
$$

The costs of $E_{2}, E_{3}$, and $E_{7}$ have been given, and then the equation may be as follows:

$$
\frac{C_{2}}{E_{2}}=\frac{C_{3}}{E_{3}}=\frac{C_{7}}{E_{7}} .
$$

The costs of $E_{4}, E_{5}$, and $E_{8}$ have been given, and then the equation will be as follows:

$$
\frac{C_{4}}{E_{4}}=\frac{C_{5}}{E_{5}}=\frac{C_{8}}{E_{8}} .
$$

According to (8)-(17), the cost of each exergy flow will be ensured.

3.3. According to the Thermoeconomic Analysis of the Solar Part, the Cost Proportions of Solar Energy in Each Exergy Flow Will Be Ensured. This part is shown in Figure 2, Box 3. For the convenience of analysis, Figure 3 has been simplified as shown in Figure 4. The system still includes six subsystems.

According to the data above, the solar energy parts in each exergy flow have just been considered alone, and the cost proportions of solar energy will be explored.

Equations of each subsystem have been given as follows.

(1) The cost equation of oil-water heat exchanging is given by the following:

$$
C_{6} \beta_{6}+C_{9} \beta_{9}+C_{n 1} \beta_{n 1}=C_{1} \beta_{1}
$$

(2) The cost equation of preheating, steam generating, and superheating is given by the following:

$$
C_{1} \beta_{1}+C_{10} \beta_{10}+C_{n 2} \beta_{n 2}=C_{2} \beta_{2} \text {. }
$$

(3) The cost equation of turbine is given by the following:

$$
C_{2} \beta_{2}+C_{n 3} \beta_{n 3}=C_{3} \beta_{3}+C_{7} \beta_{7}+C_{12} \beta_{12} \text {. }
$$

TABLE 1: Main designed parameters of coal-fired power plant.

\begin{tabular}{lcc}
\hline Parameters & Values & Units \\
\hline Capacity & 600 & $\mathrm{MW}$ \\
Parameters of main steam & $24.2 / 566 / 566$ & $\mathrm{MPa} /{ }^{\circ} \mathrm{C} /{ }^{\circ} \mathrm{C}$ \\
Feedwater mass flow rate & 1645.15 & $\mathrm{t} / \mathrm{h}$ \\
Condenser pressure & 4.9 & $\mathrm{kPa}$ \\
Feedwater temperature & 272.3 & ${ }^{\circ} \mathrm{C}$ \\
Coal consumption rate & 257.4 & $\mathrm{~g} / \mathrm{kWh}$ \\
\hline
\end{tabular}

(4) The cost equation of reheating is given by the following:

$$
C_{3} \beta_{3}+C_{11} \beta_{11}+C_{n 4} \beta_{n 4}=C_{4} \beta_{4}
$$

(5) The cost equation of turbine is given by the following:

$$
C_{4} \beta_{4}+C_{n 5} \beta_{n 5}=C_{5} \beta_{5}+C_{8} \beta_{8}+C_{13} \beta_{13} .
$$

(6) The cost equation of heat exchanging is given by the following:

$$
C_{5} \beta_{5}+C_{7} \beta_{7}+C_{8} \beta_{8}+C_{n 6} \beta_{n 6}=C_{6} \beta_{6} .
$$

Since the cost of solar energy achieving is free, we assume $C_{9}=0$ and $\beta_{9}=0$.

For the second and third subsystems, the import exergy flows of 10 and 11 will be 0 , which means the solar parts in 10 and 11 will be 0 :

$$
\beta_{10}=\beta_{11}=0 .
$$

Since the costs of $E_{2}, E_{3}$, and $E_{7}$ are equal, (25) can be obtained as follows:

$$
\beta_{2}=\beta_{3}=\beta_{7}
$$

Since the flow rates of $E_{4}, E_{5}$, and $E_{8}$ are equal, (26) can be obtained as follows:

$$
\beta_{4}=\beta_{5}=\beta_{8} .
$$

The cost proportions of solar energy $\beta$ will be ensured by using (18)-(26).

\section{Case Study}

4.1. Main Parameters. A coal-fired power plant of $600 \mathrm{MW}$ in China has been chosen as the base plant, with the main designed parameters shown in Table 1 . Coal is the supply fuel of the power plant, with the following components: moisture $=9.9 \%$, ash $=23.7 \%$, hydrogen $=3.11 \%$, nitrogen $=1.01 \%$, sulphur $=2 \%$, oxygen $=2.78 \%$, carbon $=57.5 \%$, and LHV $=$ $21981 \mathrm{~kJ} / \mathrm{kg}$.

The solar aided coal-fired power plant is using the same coal as the base case, except for the solar driven oil-water heat exchanger and the steam cut-off, other structures are the same as the base case. The data of solar field is based on real data from the GEGS-VI station in USA [9-11]. Some modifications have been made to make it suitable for the case in this 
TABLE 2: Main parameters of the collector field.

\begin{tabular}{lcc}
\hline Parameters & Values & Units \\
\hline Solar irradiation & 925 & $\mathrm{~W} / \mathrm{m}^{2}$ \\
Area of per collector & 235 & $\mathrm{~m}^{2}$ \\
Number of collector in each row & 16 & \\
Rows of collectors & 30 & Rows \\
Inlet temperature of heat transfer oil & 250 & ${ }^{\circ} \mathrm{C}$ \\
Outlet temperature of heat transfer oil & 328 & ${ }^{\circ} \mathrm{C}$ \\
\hline
\end{tabular}

TABLE 3: Main designed parameters of solar aided power plant.

\begin{tabular}{lcc}
\hline Parameters & Values & Units \\
\hline Capacity & 600 & $\mathrm{MW}$ \\
Feedwater temperature & 281.65 & ${ }^{\circ} \mathrm{C}$ \\
Coal consumption rate & 243.7 & $\mathrm{~g} / \mathrm{kWh}$ \\
Thermal efficiency & 50.41 & $\%$ \\
Exergy efficiency & 48.07 & $\%$ \\
Area of all collectors & 112800 & $\mathrm{~m}^{2}$ \\
\hline
\end{tabular}

paper. The collects are LS-2 parabolic trough collects from LUZ Company [9], and the diagram and main parameters of the collectors are shown in Table 2. The collector field is composed of 30 rows of 16 solar collectors which are parallelly installed. The heated heat transfer oil flows into the oilwater heat exchanger and the cooled heat transfer oil will be pumped back into the oil cycle.

The main designed parameters of solar aided power plant are shown in Table 3.

For the solar aided coal-fired power plant, the energy efficiency and exergy efficiency can be defined as follows:

$$
\eta_{\text {energy }}=\frac{w_{\text {output }}}{Q_{\text {coal }}+Q_{\text {solar }}},
$$

where $\eta_{\text {energy }}$ is the energy efficiency, $w_{\text {output }}$ is work output, $Q_{\text {coal }}$ is the energy of coal, and $Q_{\text {solar }}$ is the energy of solar.

$$
\eta_{\text {exergy }}=\frac{w_{\text {output }}}{E_{\text {coal }}+E_{\text {solar }}},
$$

where $\eta_{\text {exergy }}$ is the exergy efficiency, $E_{\text {coal }}$ is the exergy of coal, and $E_{\text {solar }}$ is the solar exergy.

It can be seen from Tables 1 and 3 that the coal consumption rate of solar aided coal-fired power plant is less than that of the coal-fired power plant.

The capital cost of the plant is shown in Table 4 [1218]. The investment includes the cost of facilities and the maintaining cost. The cost of coal is 140 dollars/ton [19].

4.2. Results and Sensitivity Analysis. Based on the methodology proposed in Section 3, the solar contributions in $600 \mathrm{MW}$ solar aided coal-fired power plant have been evaluated. The results of solar exergy proportion and solar cost proportion have been shown in Tables 5 and 6, respectively.

The overall exergy proportion of solar power in the plant can be calculated using $\alpha=\left(\alpha_{12} \times E_{12}+\alpha_{13} \times E_{13}\right) /\left(E_{12}+E_{13}\right)$ and the result is $4.84 \%$.
TABLE 4: The investment of the plant.

\begin{tabular}{lc}
\hline Items & Cost (dollars) \\
\hline Solar concentration field & 37528560.00 \\
Oil-water heat exchangers & 4192170.00 \\
Super heaters of the boiler & 168235561.38 \\
Reheaters of the boiler & 22941212.92 \\
High-pressure turbine & 24723323.22 \\
Intermediate-pressure turbine & 26877786.50 \\
Low-pressure turbine & 42734428.98 \\
Condenser & 14550480.00 \\
Other heat exchangers & 21149680.00 \\
Deaerator & 3156810.00 \\
Pumps & 673317.35 \\
\hline
\end{tabular}

TABLE 5: Exergy value of each flow and the proportion of solar power.

\begin{tabular}{lccc}
\hline Exergy flows Exergy value (MJ/h) & $\begin{array}{c}\text { Exergy Proportion of } \\
\text { solar } \alpha\end{array}$ & Percent \\
\hline$E_{1}$ & 555712.8 & $\alpha_{1}$ & 48.39 \\
$E_{2}$ & $\alpha_{2}$ & 6.55 \\
$E_{3}$ & 2447325 & $\alpha_{3}$ & 6.55 \\
$E_{4}$ & 1563747 & $\alpha_{4}$ & 4.09 \\
$E_{5}$ & 2065157 & $\alpha_{5}$ & 4.09 \\
$E_{6}$ & 89036.6 & $\alpha_{6}$ & 4.72 \\
$E_{7}$ & 422330.4 & $\alpha_{7}$ & 6.55 \\
$E_{8}$ & 157822.2 & $\alpha_{8}$ & 4.09 \\
$E_{9}$ & 362203.9 & $\alpha_{9}$ & 100 \\
$E_{10}$ & 357271.6 & $\alpha_{10}$ & 0 \\
$E_{11}$ & 3551430 & $\alpha_{11}$ & 0 \\
$E_{12}$ & 941377.7 & $\alpha_{12}$ & 6.55 \\
$E_{13}$ & 664758.2 & $\alpha_{13}$ & 4.09 \\
\hline
\end{tabular}

TABLE 6: Exergy cost of each flow and the proportion of solar power.

\begin{tabular}{lccc}
\hline Cost flow & values & $\begin{array}{c}\text { Cost proportion of } \\
\text { solar } \beta\end{array}$ & Percent \\
\hline$C_{1}$ & 5903 & $\beta_{1}$ & 1.98 \\
$C_{2}$ & 22724 & $\beta_{2}$ & 0.70 \\
$C_{3}$ & 14520 & $\beta_{3}$ & 0.70 \\
$C_{4}$ & 18896 & $\beta_{4}$ & 0.56 \\
$C_{5}$ & 815 & $\beta_{5}$ & 0.56 \\
$C_{6}$ & 5745 & $\beta_{6}$ & 0.70 \\
$C_{7}$ & 1465 & $\beta_{7}$ & 0.70 \\
$C_{8}$ & 3314 & $\beta_{8}$ & 0.56 \\
$C_{9}$ & 0 & $\beta_{9}$ & 100 \\
$C_{10}$ & 16181 & $\beta_{10}$ & 0 \\
$C_{11}$ & 4289 & $\beta_{11}$ & 0 \\
$C_{12}$ & 6833 & $\beta_{12}$ & 0.78 \\
$C_{13}$ & 15032 & $\beta_{13}$ & 0.62 \\
\hline
\end{tabular}


It can be seen from Table 5 that the proportion of solar exergy is 100 percent in the ninth exergy flow. This is due to the solar energy from the solar exergy flow sharing a contribution ratio of 100 percent. As exergy flows, the proportion of solar exergy shows a decreasing trend. The twelfth and the thirteenth exergy flows shown in Table 5 represent the exergy in system work (i.e., electric power). The proportions of solar power are $6.55 \%$ and $4.09 \%$. The overall exergy proportion of solar power is $4.84 \%$ by weighing the proportions in the twelfth and thirteenth exergy flows. In the system, considering the proportion of exergy flows, the contribution of solar power can be measured by its proportion of $4.84 \%$ in the overall electric power. For the system with a rated capacity of $600 \mathrm{MW}$, in this case, about 29.04 MW of electric power is contributed to solar power and the rest $570.96 \mathrm{MW}$ is contributed to coal-fired.

The overall cost proportion of solar power in the plant can be calculated using $\beta=\left(\beta_{12} \times C_{12}+\beta_{13} \times C_{13}\right) /\left(C_{12}+C_{13}\right)$ and the result is $0.67 \%$.

It can be seen from Table 6 that the cost of solar exergy flow is zero in the exergy cost of the ninth flow. This is because the solar energy has been considered to be free in the analysis. The exergy cost of the twelfth and thirteenth flows in Table 6 shows the exergy costs of electricity, and the proportions of solar power are $0.78 \%$ and $0.62 \%$ in them. By weighing the proportions of solar power in the twelfth and thirteenth flows, we can obtain that the proportion of solar power in the electric exergy cost is $0.67 \%$. In this system, considering the exergy cost of flows, the proportion of the cost of solar power and solar equipments is $0.67 \%$. For the system, a rated capacity of $600 \mathrm{MW}$, in this case, the cost of solar energy, and solar equipment share a proportion of $0.67 \%$ in the cost of electric power, and the rest (99.33\%) comes from coal and other equipment. Comparing the calculated solar power exergy generated with the proportion of cost of solar power exergy generated, the proportion of $4.48 \%$ of solar power exergy generated is much larger than the proportion of $0.67 \%$ of cost of solar power exergy generated.

(1) Sensitivity Analysis of Coal Cost. When the coal cost changes from 100 to 180 dollars/ton, the trend of cost of electricity is shown in Figure 5 and the trend of the overall cost proportion of solar is shown in Figure 6.

The power generation cost is calculated as follows:

$$
c_{\text {electricity }}=\frac{C_{\text {electricity }}}{E_{\text {electricity }}}
$$

where $c_{\text {electricity }}$ is the cost of power generation, $C_{\text {electricity }}$ is the exergy cost of electricity, and $E_{\text {electricity }}$ is the generating capacity.

The exergy cost of electricity includes two aspects, namely, fixed costs and variable costs. The fixed costs include equipment costs, material costs, depreciation costs, operation, and maintenance fees, and the variable costs include fuel costs, environmental costs, water charges. In order to take advantage of the calculation method proposed in this paper, all of the costs (except the fuel costs) have been converted to

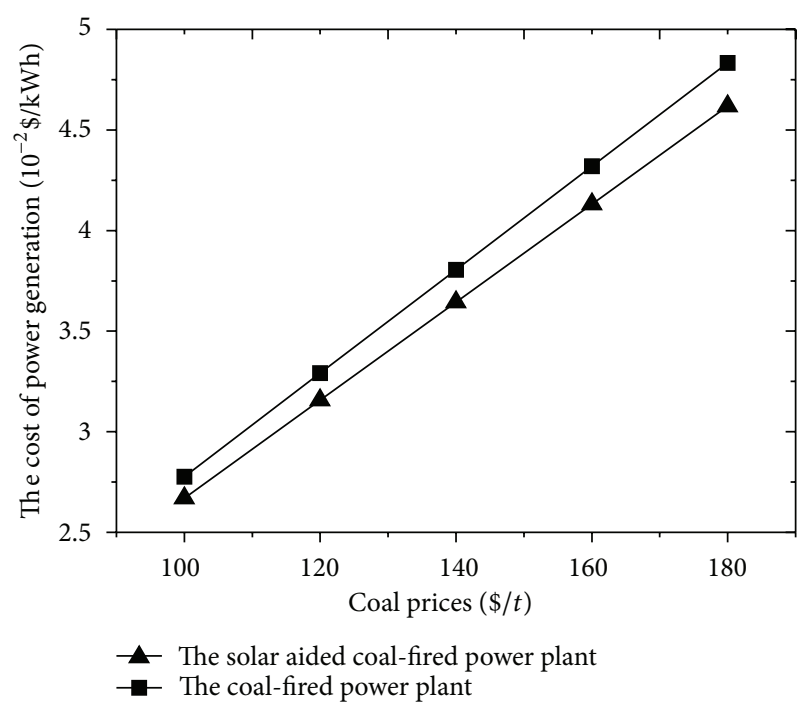

FIGURE 5: The change of cost of electricity with coal cost.

the equipment costs. Therefore, in this case, the cost of power generation is calculated as follows:

$$
c_{\text {electricity }}=\frac{C_{12}+C_{13}}{E_{12}+E_{13}} .
$$

It can be seen from Figure 5 that the cost of electricity increases from 2.67 cents $/ \mathrm{kWh}$ to 4.62 cents/kWh in the solar aided coal-fired power plant with the coal prices increase from $100 \$ / t$ to $180 \$ / t$. The power generation cost of $600 \mathrm{MW}$ power plant is 3.81 cents/kWh, and that of the coupled power plant power is 3.64 cents $/ \mathrm{kWh}$ when the coal price is $140 \$ / \mathrm{t}$. In the terms of coal price, the COE of a solar aided power plant is less than the one of coal-fired power plant. As solar energy is added to the solar aided system, in the condition of saving coal (with lower coal consumption rate), considering the solar energy is free, the COE of a coupled power plant will be lower than the original thermal power plant. However, compared to the pure solar power generation system, the coupled system uses the turbines, generators and other key equipment of the original thermal power system, and the work efficiency of the replaced high-temperature high-pressure high-grade steam is much higher than the pure solar thermal power generation. Therefore, the $\mathrm{COE}$ of the coupled power generation system is less than the pure solar power generation system.

It can be seen from Figure 6 that with the coal price increasing from $100 \$ / t$ to $180 \$ / t$, the $\beta$ is reduced from $0.92 \%$ to $0.51 \%$, about 0.41 points. The reduction trend tends to be slower with the increase of the coal price.

(2) Sensitivity Analysis of Solar Facilities' Investment. When the investment of solar facilities changes from $60 \%$ to $140 \%$, the trend of the cost of electricity is shown in Figure 7 and the trend of the overall cost proportion of solar is shown in Figure 8.

Figure 7 shows that, with the solar equipment price increase, the proportion of solar equipment increases in the 


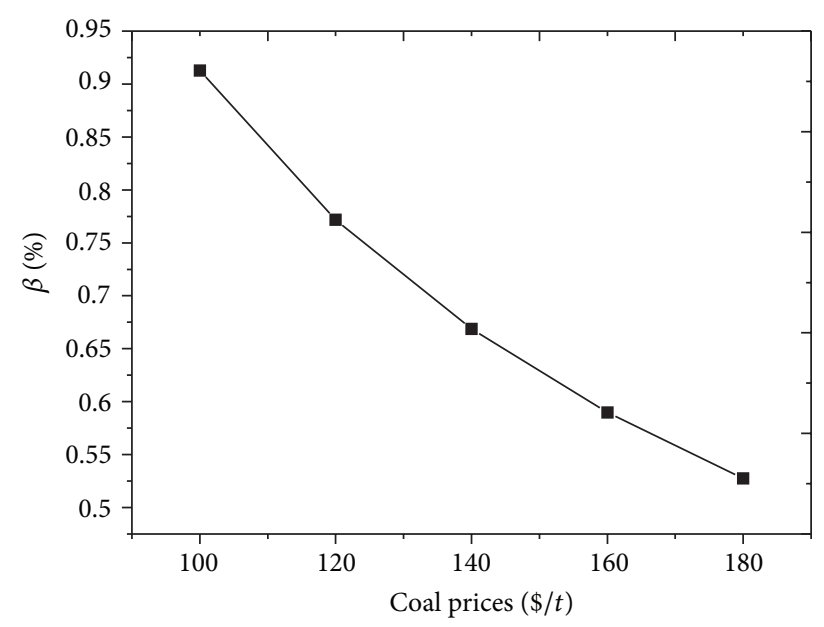

Figure 6: The change of the overall cost proportion of solar with coal cost.

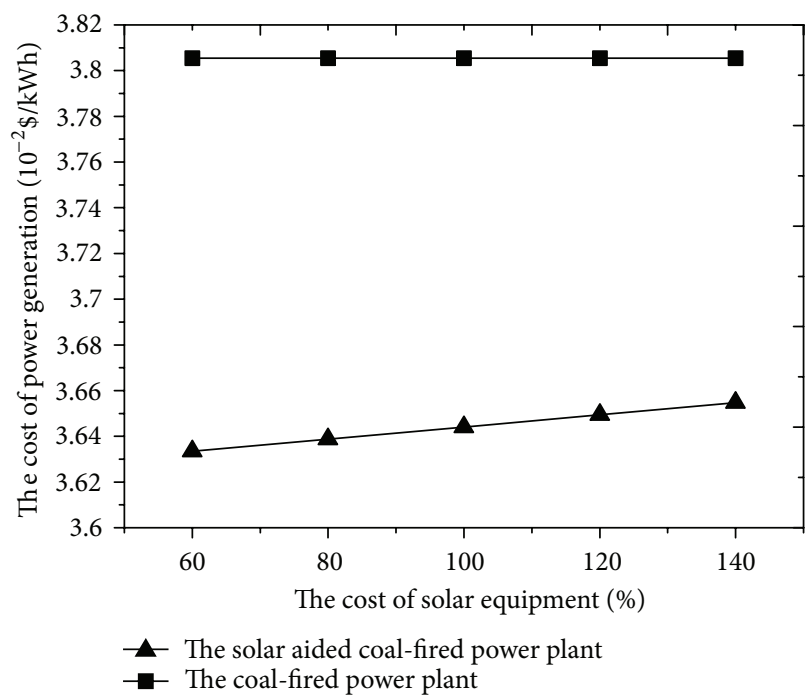

FIGURE 7: The change of the cost of electricity with the solar facilities' investment.

equipment costs, so the COE of solar aided power plant increases. Therefore, the production of cheap solar collector devices is good for power plant in low-cost operation.

It can be seen from Figures 7 and 8, with the change of the cost of solar equipment from $60 \%$ of the calculation cost to $140 \%$ of the calculation cost, that the cost of power generation increases from 3.63 cents $/ \mathrm{kWh}$ to 3.65 cents $/ \mathrm{kWh}$; the $\beta$ increases from $0.53 \%$ to $0.79 \%$, which is about 0.26 points.

\section{Conclusions}

This paper proposed thermoeconomic cost method for solar contribution study in solar aided coal-fired power plant and analyzed the plant based on the newly constructed and reconstructed $600 \mathrm{MW}$ power plant.

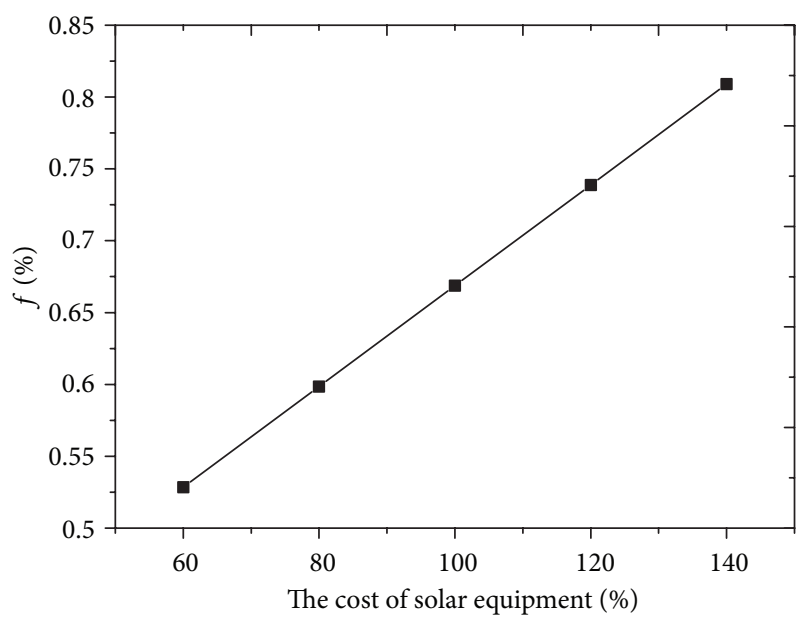

FIGURE 8: The change of the overall cost proportion of solar with the solar facilities' investment.

Based on the second law of thermodynamics and the principle of thermoeconomics, this paper proposed the evaluation of solar contribution in the solar aided coal-fired power plant, which can be used to assign the individual cost components involving solar energy. Its feasibility has been proven by analyzing a newly constructed power plant. The result shows: that when operating at the rated capacity, the proportion of solar power in overall electric power is $4.84 \%$, which is about $29.04 \mathrm{MW}$.

\section{Nomenclature}

$E_{i}$ : The exergy value of the $i$ th exergy flow

$\delta_{i}$ : The ratio of solar exergy loss in the total exergy loss when running the $i$ th equipment

$\alpha_{i}$ : The ratio of solar exergy flow in the $i$ th exergy flow

$c_{i}$ : The unit cost of the $i$ th exergy flow

$C_{i}: C_{i}=c_{i} \cdot E_{i}$. The cost of the $i$ th exergy flow, as the energy cost

$C_{\gamma i}:$ The nonenergy cost of the $i$ th subsystem

$\beta_{i}$ : The exergy cost ratio of the solar contribution in the $i$ th exergy flow

$\beta_{\gamma i}$ : The ratio of the solar side of the nonenergy costs of the $i$ th subsystem.

\section{Acknowledgments}

The research work is supported by China National Natural Science Foundation (no. 51106048), the Fundamental Research Funds for the Central Universities and the Program for 863 Project (2012AA050604). The authors have no other relevant affiliations or financial involvement with any organization or entity with a financial interest in or financial conflict with the subject matter or materials discussed in the paper apart from the one disclosed. 


\section{References}

[1] D. Mills, "Advances in solar thermal electricity technology," Solar Energy, vol. 76, no. 1-3, pp. 19-31, 2004.

[2] B. R. Pai, "Augmentation of thermal power stations with solar energy," Sādhanā, vol. 16, no. 1, pp. 59-74, 1991.

[3] M. K. Gupta and S. C. Kaushik, "Exergetic utilization of solar energy for feed water preheating in a conventional thermal power plant," International Journal of Energy Research, vol. 33, no. 6, pp. 593-604, 2009.

[4] Y. M. El-Sayed and R. A. Gaggioli, "Critical review of second law costing methods-I: background and algebraic procedures," Journal of Energy Resources Technology, vol. 111, no. 1, pp. 1-7, 1989.

[5] R. A. Gaggioli and Y. M. El-Sayed, "Critical review of second law costing methods-II: calculus procedures," Journal of Energy Resources Technology, vol. 111, no. 1, pp. 8-15, 1989.

[6] M. A. Rosen and I. Dincer, "Thermoeconomic analysis of power plants: an application to a coal fired electrical generating station," Energy Conversion and Management, vol. 44, no. 17, pp. 2743-2761, 2003.

[7] M. V. J. J. Suresh, K. S. Reddy, and A. K. Kolar, "4-E (energy, exergy, environment, and economic) analysis ofsolar thermal aided coal-fired power plants," Energy for Sustainable Development, vol. 14, no. 4, pp. 267-279, 2010.

[8] A. Baghernejad and M. Yaghoubi, "Exergoeconomic analysis and optimization of an Integrated Solar Combined Cycle System (ISCCS) using genetic algorithm," Energy Conversion and Management, vol. 52, no. 5, pp. 2193-2203, 2011.

[9] A. M. Patnode, Simulation and performance evaluation of parabolic trough solar power plants [Ph.D. thesis], University of Wisconsin, Madison, Wis, USA, 2006.

[10] T. Stuetzle, Automatic control of the 30MWe SEGS VI parabolic trough plant [M.S. thesis], University of Wisconsin, Madison, Wis, USA, 2002.

[11] T. Stuetzle, N. Blair, J. W. Mitchell, and W. A. Beckman, "Automatic control of a 30 MWe SEGS VI parabolic trough plant," Solar Energy, vol. 76, no. 1-3, pp. 187-193, 2004.

[12] M. A. Lozano, A. Valero, and L. Serra, "Theory of the exergetic cost and thermoeconomics optimization," in Proceedings of the International Symposium on International Conference on Energy Systems and Ecology (ENSEC '93), Cracow, Polland, 1993.

[13] C. Frangopoulos, Thermoeconomic functional analysis: a method for optimal design or improvement of complex thermal systems [Ph.D. thesis], Georgia Institute of Technology, 1983.

[14] M. R. von Spakovsky, A practical generalized analysis approach to the optimal thermoeconomic design and improvement of real-world thermal systems [Ph.D. thesis], Georgia Institute of Technology, 1986.

[15] J. Uche, Thermoeconomic analysis and simulation of a combined power and desalination plant [Ph.D. thesis], Department of Mechanical Engineering, University of Zaragoza, 2000.

[16] J. Uche, L. Serra, and A. Valero, "Thermoeconomic optimization of a dual-purpose power and desalination plant," Desalination, vol. 136, no. 1-3, pp. 147-158, 2001.

[17] J. L. Silveira and C. E. Tuna, "Thermoeconomic analysis method for optimization of combined heat and power systems. Part I," Progress in Energy and Combustion Science, vol. 29, no. 6, pp. 479-485, 2003.

[18] Y. Yang, Y. Cui, H. Hou, X. Guo, Z. Yang, and N. Wang, "Research on solar aided coal-fired power generation system and performance analysis," Science in China, Series E, vol. 51, no. 8, pp. 1211-1221, 2008.

[19] B. Zhang and J. Ma, "Coal price index forecast by a new partial least-squares regression," Procedia Engineering, vol. 15, pp. 5025-5029, 2011. 

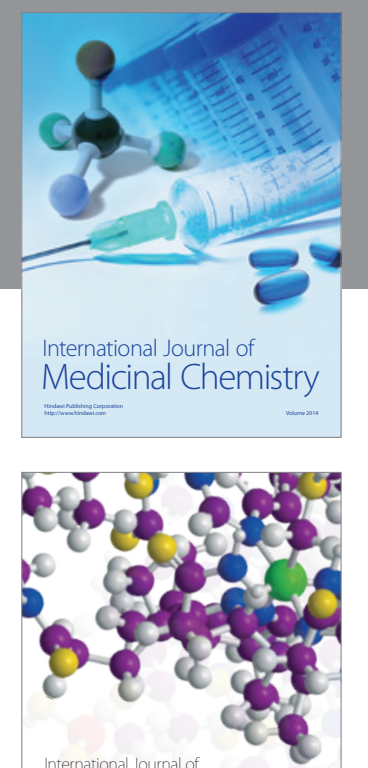

\section{Carbohydrate} Chemistry

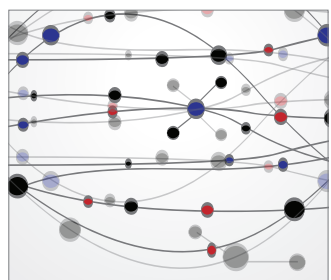

The Scientific World Journal
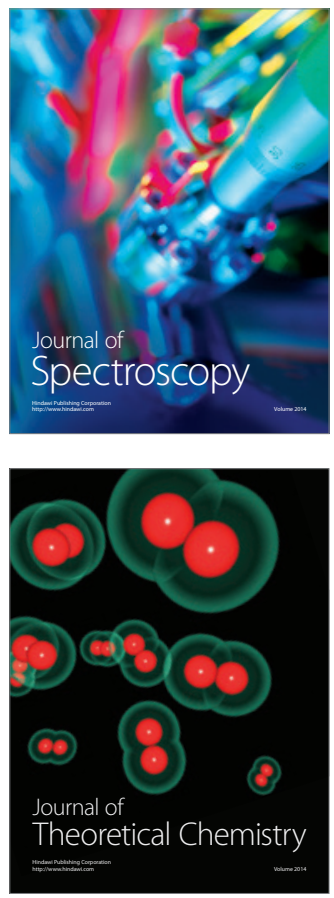
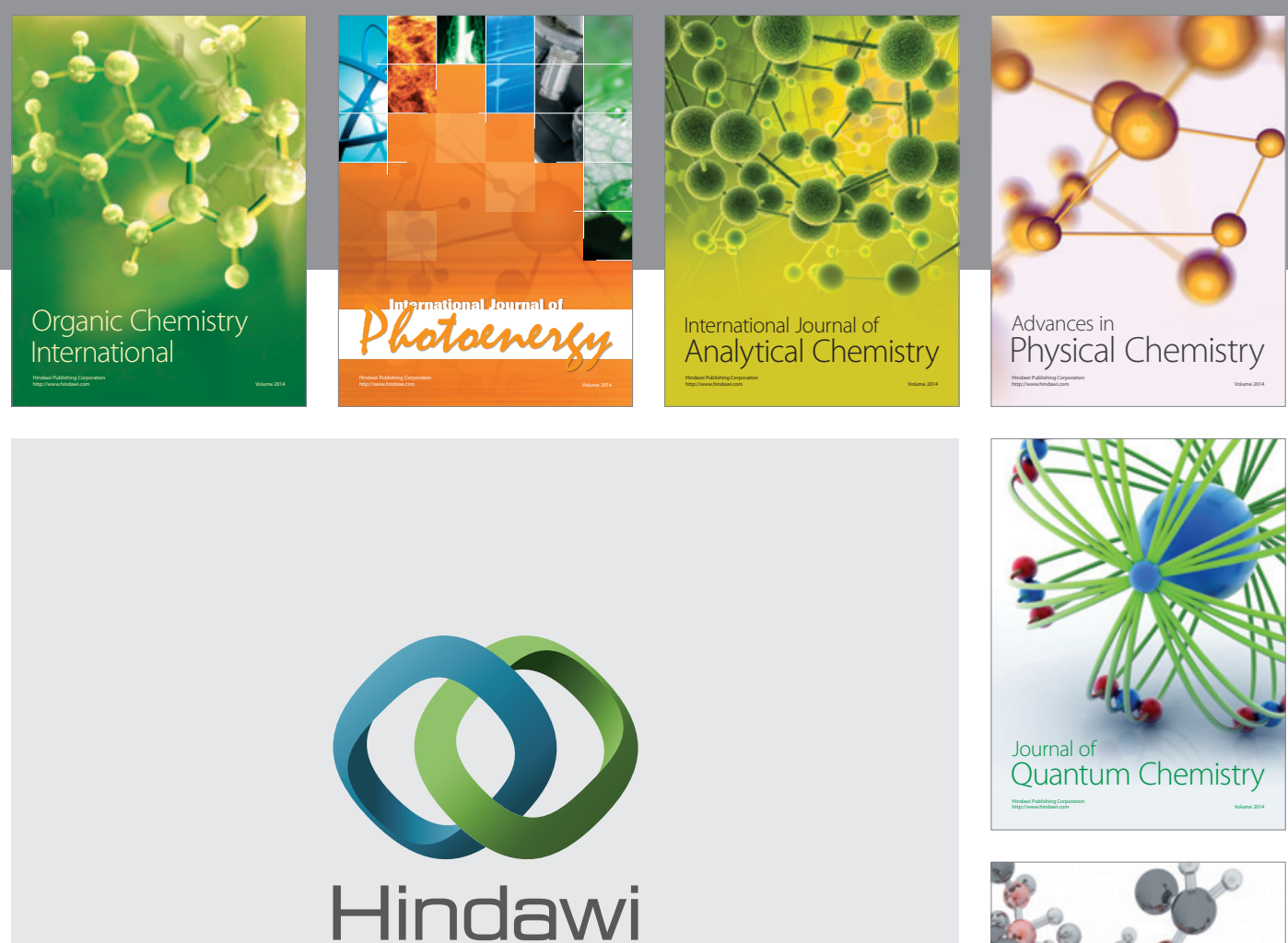

Submit your manuscripts at

http://www.hindawi.com

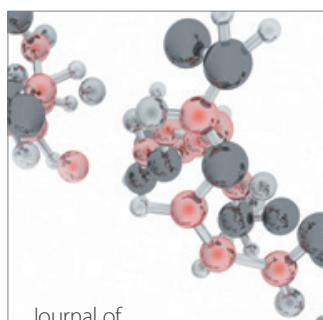

Analytical Methods

in Chemistry

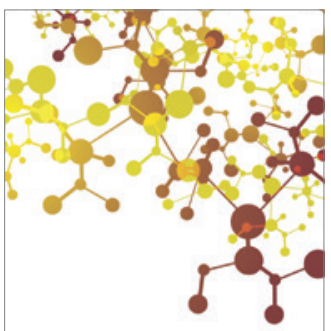

Journal of

Applied Chemistry

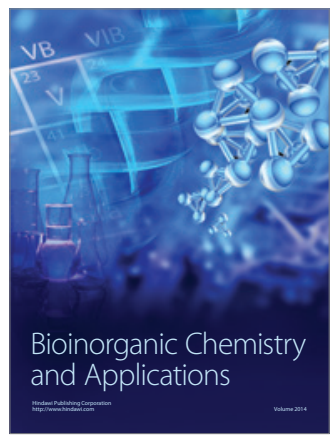

Inorganic Chemistry
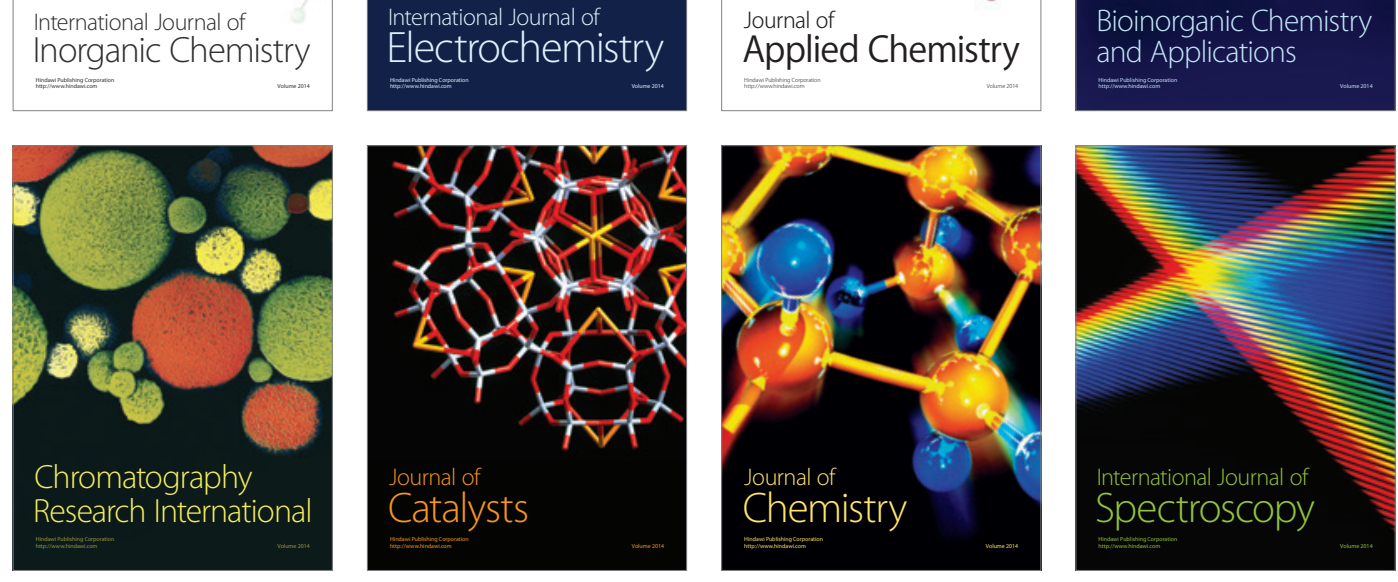